9 Siegel JE, Torrance GW, Russell LB, Luce BR, Weinstein MC, Gold MR. Guidelines for pharmacoeconomic studies. Recommendations from the Panel on Cost Effectiveness in Health and Medicine. Pharmacoeconomics 1997; 11: $159-68$.

10 Torrance GW, Blaker D, Detsky A, Kennedy W, Schubert F, Menon D, et al. Canadian guidelines for economic evaluation of pharmaceuticals. Canadian Collaborative Workshop for Pharmacoeconomics. Pharmacoeconomics 1996; 9: 535-59.

11 Van Hout BA, Al MJ, Gordon GS, Rutten FF. Costs, effects and C/E-ratios alongside a clinical trial. Health Econ 1994; 3: 309-19.

12 Barrett B, Byford S. Acceptable mental health care? A new decision-making tool for cost-effectiveness analysis. Ment Health Res Rev 2003; 9: 39-41.

13 Willemse GR, Smit F, Cuijpers P, Tiemens BG. Minimal-contact psychotherapy for sub-threshold depression in primary care: randomised trial. Br J Psychiatry 2004; 185: 416-21.
14 Smit F, Willemse G, Koopmanschap M, Onrust S, Cuijpers P, Beekman A. cost-effectiveness of preventing depression in primary care patients: randomised trial. Br J Psychiatry 2006; 188: 330-6.

15 Simon GE, Katon WJ, Von Korff M, Unutzer J, Lin EH, Walker EA, et al. Cost-effectiveness of a collaborative care program for primary care patients with persistent depression. Am J Psychiatry 2001; 158: 1638-44.

16 Cuijpers $\mathrm{P}$, Van Straten A, Smit F, Mihalopoulos C, Beekman A. Preventing the onset of depressive disorders: a meta-analytic review of psychological interventions. Am J Psychiatry 2008; 165: 1272-80.

17 Van Schaik DJ, Klijn AF, van Hout HP, van Marwijk HW, Beekman AT, de Haan $\mathrm{M}$, et al. Patients' preferences in the treatment of depressive disorder in primary care. Gen Hosp Psychiatry 2004; 26: 184-9.
Psychiatry in music

\title{
Robert Schumann's contribution to the genetics of psychosis
}

\section{Katharina Domschke}

Robert Schumann (1810-1856), one of the most influential romantic composers, had a lifelong mental disorder, first manifesting in 1833 as a severe melancholic depressive episode, which recurred several times alternating with phases of 'exaltation' and increasingly also delusional ideas of being poisoned or threatened with metallic items. After a suicide attempt, Schumann was admitted to a mental asylum in Endenich near Bonn and diagnosed with 'psychotic melancholia'. He died in Endenich without having recovered from his mental illness.

Hypothetical diagnoses of Schumann's ailments vary from progressive paralysis to hypertensive encephalopathy, with the most compelling evidence being for either schizophrenia ('dementia praecox'; 'periodic catatonia') or bipolar disorder and bipolar II disorder. Delusional ideas, ideas of reference as well as acoustic hallucinations support a diagnosis on the schizophrenic spectrum. However, the notion of Schumann having a bipolar disorder possibly with psychotic features is substantiated by the undulating course of his illness with distinct depressive and hypomanic phases as well as his recovery from single episodes with full restoration of his musical and compositional abilities.

Given the still ongoing clinical debate about Schumann's diagnosis, a more detailed analysis of his pedigree might help to elucidate the nature of his disease. Therefore, a hypothetical pedigree based on descriptions of Schumann's ancestry (Bienenfeld, E., Archiv für Rassen- und Gesellschaftsbiologie (1932) \& Lindner, A., Genealogie (1974)) is proposed here (Fig. 1)

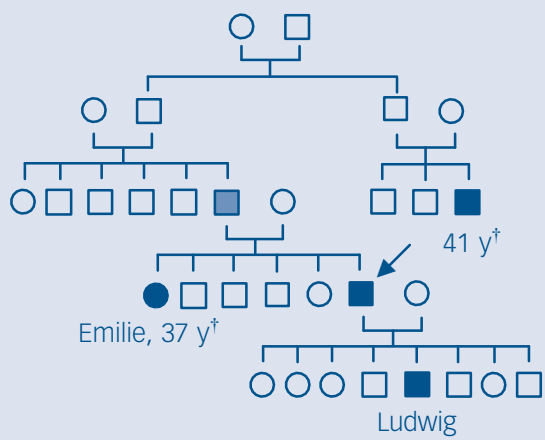

Fig. 1 Robert Schumann's hypothetical pedigree with respect to the segregation of mental disorders

Square - male; circle - female; arrow - index person Robert Schumann; black filling - affected by mental disorder; black/white shadowed - possibly affected by mental disorder; "death by suicide.

Apart from Schumann himself, his sister Emilie experienced 'a never-healing mental disorder, which intermittently carried traits of silent insanity as horrible sequelae of this disease', which retrospectively can most probably be diagnosed as schizophrenia, and died by suicide at the age of 37 . Also, his son Ludwig is reported to have had a severe, probably schizophreniform mental disorder, which necessitated admission to a mental asylum at the age of 28 , where he lived for another 25 years without recovering from his illness. Schumann's father Friedrich August, otherwise successful as a publisher, is described as melancholic and 'sensitive close to insanity'. Finally, a cousin of Schumann's father's died by suicide at the age of 41 , probably having had an affective mental disorder.

Obviously, mental disorders have segregated in Robert Schumann's family, which strengthens the notion of either bipolar disorder or schizophrenia, rather than progressive paralysis, to underlie Schumann's symptomatology. Given that his symptoms cannot conclusively be attributed to either schizophrenia or bipolar disorder and that in his family both psychotic and affective disorders or symptoms can be discerned, a schizophrenia-bipolar spectrum rather than a clear-cut Kraepelinian dichotomy might be proposed for mental disorders segregating in Schumann's family. This is in line with clinical and epidemiological observations of a continuum between schizophrenia and bipolar disorder, both considered complex genetic disorders with similarly high heritability of 85-93\%. Consistently, linkage studies report risk loci common for schizophrenia and bipolar disorder, particularly on chromosomes 8p22. $10 p 14,13 q 32,18 p 11,22 q 11$ and $6 p$ and there is molecular genetic evidence of candidate genes influencing the disease risk of both schizophrenia and bipolar disorder: G72(DAOA)/G30 on chromosome 13q48, DISC1 at 1q42, neuregulin 1 (NRG1) at 8p21-22 and catechol-0-methyltransferase (COMT) on chromosome 22q11. Additionally, a linkage study analysing families of probands meeting criteria for schizoaffective disorder strongly supports the existence of loci that provide specific susceptibility to psychosis with both schizophrenic and bipolar features at chromosome 1q42 and possibly also at 22q11 and 19p13. Thus, given an aggregation of both affective and psychotic disorders in Robert Schumann's family and his own symptoms with both affective and psychotic features, here schizoaffective disorder or a 'schizoaffective spectrum phenotype' with a major genetic susceptibility conferred by overlapping sets of genes is proposed as a differential diagnosis of Schumann's mental disorder. 